\title{
A catalyst for change
}

Early release. Published at www.cmaj.ca on Feb. 24, 2006.

$\mathrm{T}$ he Journal's Editor in Chief, John Hoey, and Senior Deputy Editor, Anne Marie Todkill, were dismissed on Feb. 20, 2006. Their departure is a blow to the $C M A J$, Canadian physicians and the international scientific and medical communities.

Hoey and Todkill started at the Journal in 1996 and 1994 respectively. Both are immensely talented, world-class editors committed to excellence and integrity in scientific research and news reporting and to a consideration of the broader social context of medicine. Thanks to their stewardship, $C M A J$ has become a leading international medical journal: the Journal's impact factor has tripled to 5.9, and cmaj.ca, which was launched during their tenure, now receives more than 250 ooo page views per month.

Hoey is a respected internist, epidemiologist and public health physician. His affable personality, unflappable nature and considerable intellect were excellent qualifications for his role in shepherding CMAJ. Todkill founded The Left Atrium - an arts and humanities section devoted to the creative, reflective and sometimes hidden face of medicine and edited the Query column, each of which has struck a chord with our readers. We will miss her penetrating queries, grasp of logic, masterly command of the English language and sage counsel.

Under Hoey and Todkill's guidance, the Journal tackled important topics in its lead editorials on medicine and health care; they did not shy away from controversial issues such as the decriminalization of marijuana, emergency department staffing in Quebec, abortion, medicare, emergency contraception, health care privatization and editorial independence. They stood steadfast by their principles and ignited change; whether you agreed with the editorials or not, their enrichment of the discourse of medicine is undeniable.

We recognize that it is the prerogative of the owners of any journal to hire and fire its editors. However, the remaining editors of $C M A J$ disagree with and protest the recent decision. ơ We remain because we believe that it is crucial to uphold and build on what Hoey and Todkill achieved. The Journal has become an important forum for discussion and dissemination of high-quality original research papers, review articles and news items that help to guide the practice of medicine. This should not be jeopardized.
Legally, CMA Holdings owns the Journal, but in a wider sense it belongs to patients, clinicians, authors and readers. In line with Hoey and Todkill's recent efforts, ${ }^{1}$ we feel a responsibility to this community to call for measures that guarantee the editorial independence of $C M A J$ once and for all. $C M A J$ can remain a leading medical journal with international repute only if its editors are free to make editorial decisions without interference.

In the meantime, we feel a deep sadness at the absence of our two colleagues, leaders and friends.

For our part - to ensure a swift resolution to this issue we have drafted a proposal outlining our vision for an independent $C M A J$. We welcome input from our Editorial Board, Publisher, the Journal Oversight Committee (JOC) and the CMA.

We thank the members of our editorial board for their tremendous support and will look to them for ongoing guidance. We are grateful to members of the advisory group who were asked to review $C M A F$ s editorial autonomy and governance structure. Their report is included in this issue of the Journal. A statement from the Chairs of the CMA Board of Directors and the JOC about editorial independence is also included in this issue.

\section{Stephen Choi \\ Acting Editor \\ Ken Flegel \\ Associate Editor \\ Claire Kendall \\ Associate Editor \\ Anita Palepu \\ Associate Editor \\ Eric Wooltorton \\ Associate Editor \\ Sally Murray \\ Editorial Fellow \\ Nick Barrowman \\ Statistical Consultant \\ CMAJ}

\section{REFERENCE}

I. The editorial autonomy of $C M A J$ [editorial]. $C M A J$ 2006;174(I):9. 